Supporting Information Available

\title{
Temperature- and pH-Dependent Morphology and FT-IR Analysis of Magnesium Carbonate Hydrates
}

\section{Zhiping Zhang, ${ }^{a}$ Yajun Zheng, ${ }^{\mathrm{b}}$ Yuwen Ni, ${ }^{\mathrm{a}}$ Zhongmin Liu, ${ }^{\mathrm{a}}$ Jiping Chen ${ }^{\mathrm{a} *}$ and Xinmiao Liang ${ }^{\text {a }}$}

${ }^{a}$ Dalian Institute of Chemical Physics, Chinese Academy of Sciences, 457 Zhongshan Road, Dalian 116023, China

${ }^{b}$ Institute of Chemistry for Functionalized Materials, Department of Chemistry, Liaoning Normal University, Dalian 116029, China

1. The TG and DTG graphs of the particles from $318 \mathrm{~K}$ and $348 \mathrm{~K}$
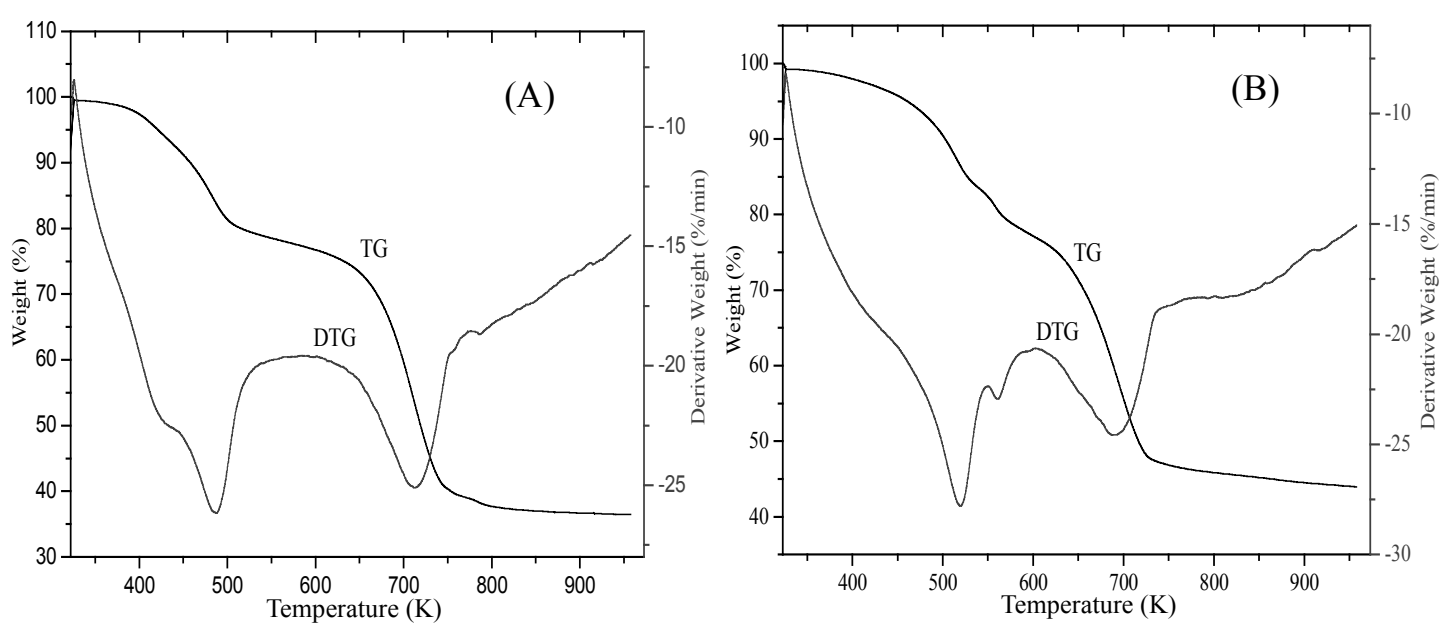

Figure 1. TG and DTG graphs of the particles from $318 \mathrm{~K}$ (A) and $348 \mathrm{~K}$ (B)

For the sample from $318 \mathrm{~K}$, the first weight loss in the range of $303-533 \mathrm{~K}$ is $20.9 \%$ as shown in Figure 1A. After careful observation of DTG, it can be noted that there are two peaks in this range. The major peak is around $523 \mathrm{~K}$, and the other one exists as a shoulder peak at about $423 \mathrm{~K}$. According to the report of Hong et al., ${ }^{1}$ the two 
peaks should be ascribed to different types of water of crystallization. The first one is the water of crystallization in the particle, and the following one is the mixture of the water of crystallization and structure water. In the range of 548-873 $\mathrm{K}$, a second weight loss $(41.9 \%)$ appears, which is attributed to the decomposition of $\mathrm{MgCO}_{3}$ to $\mathrm{MgO}$.

For the sample from $348 \mathrm{~K}$, the first weight loss in the range of $323-553 \mathrm{~K}$ is $17.1 \%$, which is due to the loss of absorbed water and water of crystallization. The second weight loss is only $4.8 \%$, observed in the range of 553-588 $\mathrm{K}$, which should be attributed to the decomposition of $\mathrm{Mg}(\mathrm{OH})_{2}$ to $\mathrm{MgO}$. The third weight loss (34.3\%) is observed at $588-918 \mathrm{~K}$, which is attributed to the decomposition of $\mathrm{MgCO}_{3}$ to $\mathrm{MgO}$.

After a rough calculation of both results, the sample from $318 \mathrm{~K}$ has a simple formula of $\mathrm{MgCO}_{3} \cdot 1.3 \mathrm{H}_{2} \mathrm{O}$. For the sample from $348 \mathrm{~K}$, it has a formula of $\mathrm{Mg}_{5}\left(\mathrm{CO}_{3}\right)_{4}(\mathrm{OH})_{2} \cdot 4 \mathrm{H}_{2} \mathrm{O}$.

\section{The variety of IR spectra with the change of calcination temperature}

For confirming the band at $2344 \mathrm{~cm}^{-1}$, a series of samples have been prepared in an open-column of gas chromatography under $\mathrm{N}_{2}$ atmosphere with the temperature rising from $303 \mathrm{~K}$ to $373,423,473,523$ and $573 \mathrm{~K}$ with the rate of $10 \mathrm{~K} / \mathrm{min}$, then keeping for $30 \mathrm{~min}$ because the dehydration temperature and decomposition temperature of bicarbonate ions in $\mathrm{MgCO}_{3} \cdot 3 \mathrm{H}_{2} \mathrm{O}$ and $\mathrm{Mg}_{5}\left(\mathrm{CO}_{3}\right)_{4}(\mathrm{OH})_{2} \cdot 4 \mathrm{H}_{2} \mathrm{O}$ were in the ranges of 383-473 K and 473-653 K, respectively, ${ }^{1}$ and the change of the IR spectra have been investigated.

As shown in Figure 2, the IR spectra of the particles obtained from the room temperature vary significantly with the increase of calcination temperature. When the calcination temperature is $373 \mathrm{~K}$, there isn't any trace of the band at $2344 \mathrm{~cm}^{-1}$. With the increase of temperature up to $423 \mathrm{~K}$, the band begins to appear, which suggests that some bicarbonate ions in the particle have decomposed because the band at 985 $\mathrm{cm}^{-1}$ can be assigned as the characteristic absorption band of bicarbonate ions. Further 
increasing the calcination temperature to $473 \mathrm{~K}$ results in the disappearance of the latter band, and the former one becomes stronger. At the same time, it can be observed that the band at $3130 \mathrm{~cm}^{-1}$ also disappears, which suggests that some water of crystallization have been lost in the range of 423-473 K. When the calcination temperature is increased up to $473-573 \mathrm{~K}$, the band at $2344 \mathrm{~cm}^{-1}$ becomes more and more strong, which indicates that with the increase of calcination temperature, a lot of bicarbonate ions in the particle may have decomposed, and the produced $\mathrm{CO}_{2}$ exits as a terminal or absorption form on the surface of the particles.

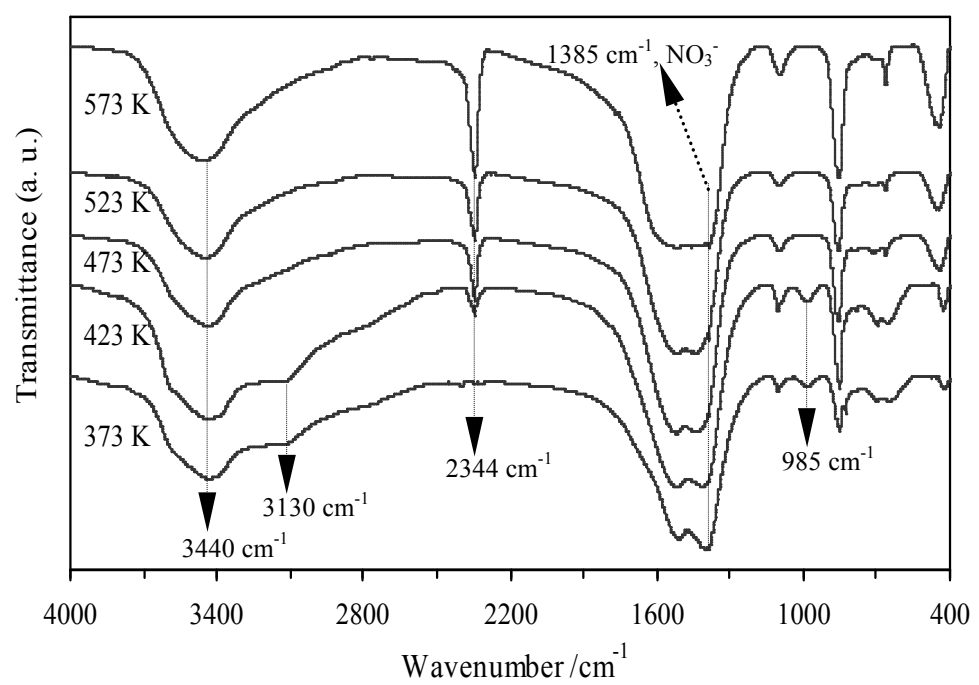

Figure 2. FT-IR spectra of the particle from room temperature after calcination at various temperatures

For the particles obtained from other temperatures and a lower $\mathrm{pH}$ value at $318 \mathrm{~K}$, the IR spectra have the same change patterns, which can be clearly seen from Figure 3 and 4. At the same time, it can be noted that there is a band around $3440 \mathrm{~cm}^{-1}$ even for the particles calcined at $573 \mathrm{~K}$, which results from the absorbed water on $\mathrm{KBr}$ as shown in Figure 5. 


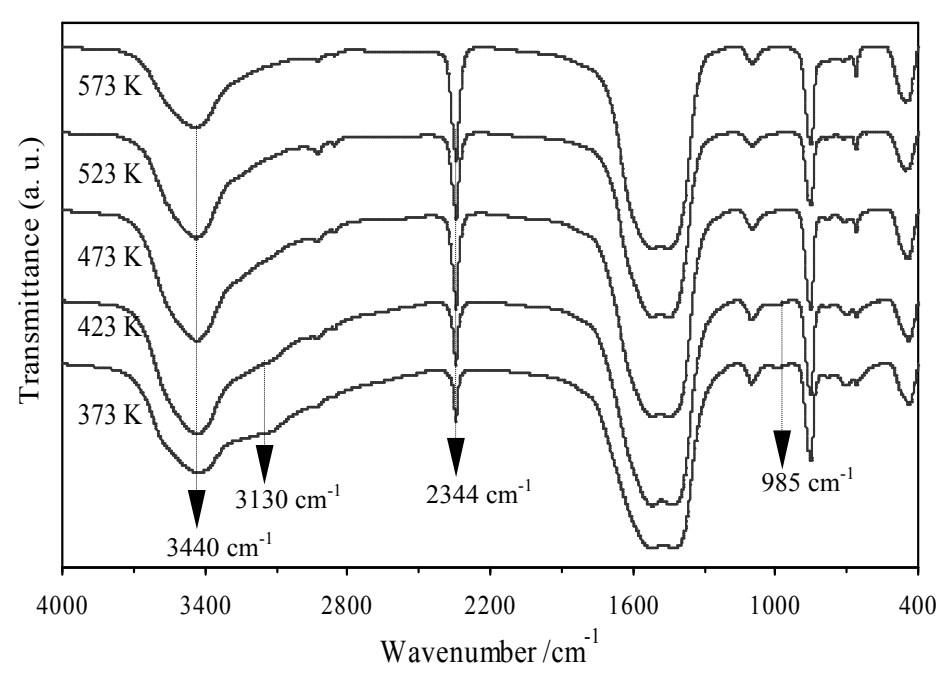

Figure 3. FT-IR spectra of the particles from $\mathrm{pH}=9.5$ at $318 \mathrm{~K}$ after calcination at various temperatures

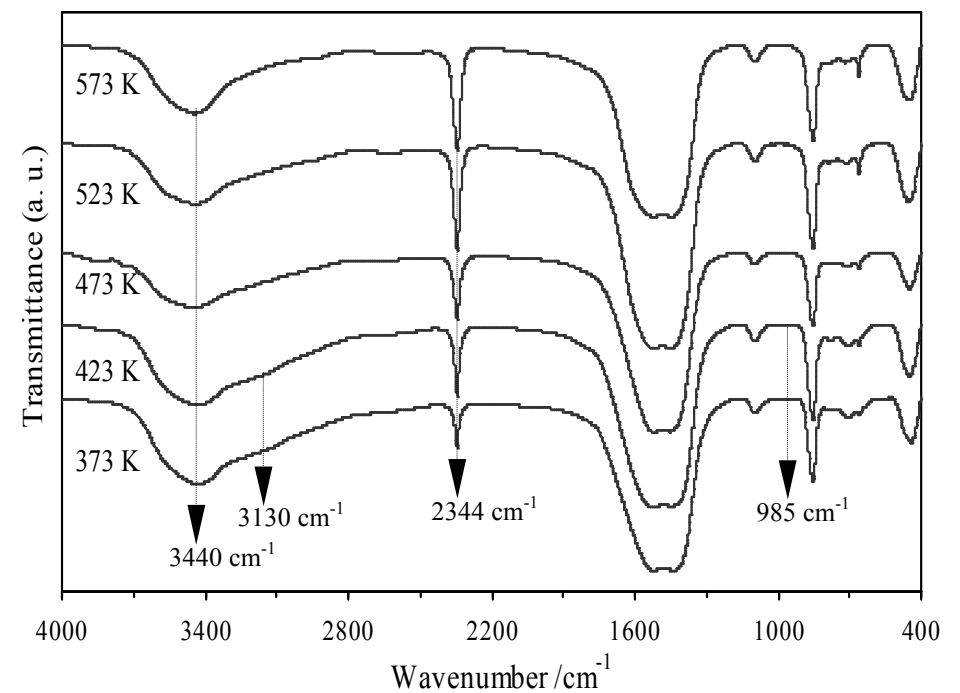

Figure 4 FT -IR spectra of the particles from $\mathrm{pH}=11.5$ at $318 \mathrm{~K}$ after calcination at various temperatures

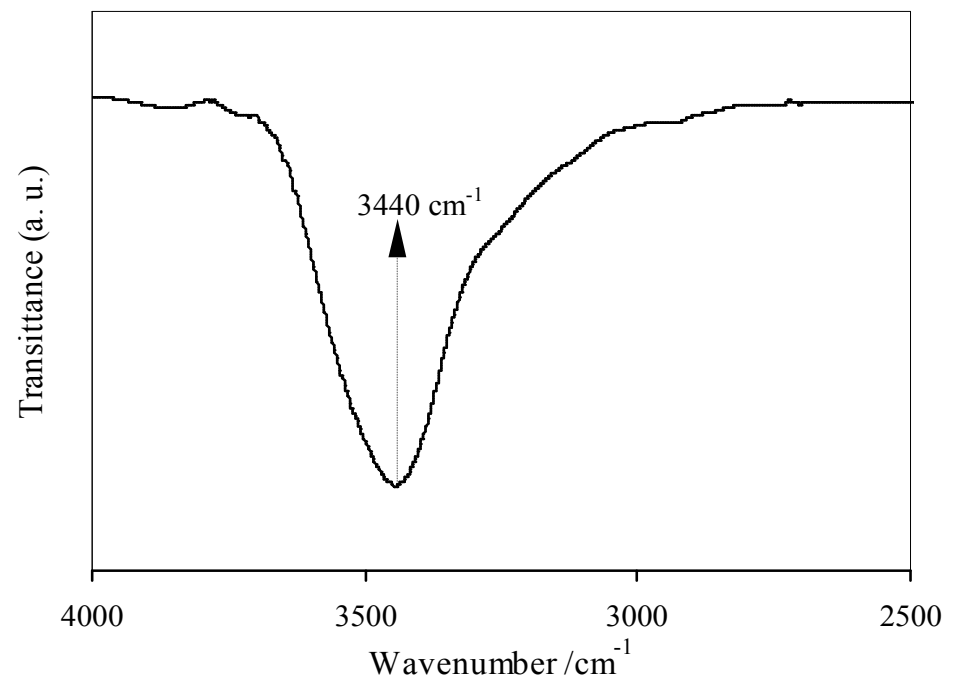

Figure 5. FT-IR spectra of $\mathrm{KBr}$ 
2. The TG and DTG graphs of the particles from $\mathrm{pH}=11.5$ at $318 \mathrm{~K}$ and from $\mathrm{pH}=8.5$ at $338 \mathrm{~K}$
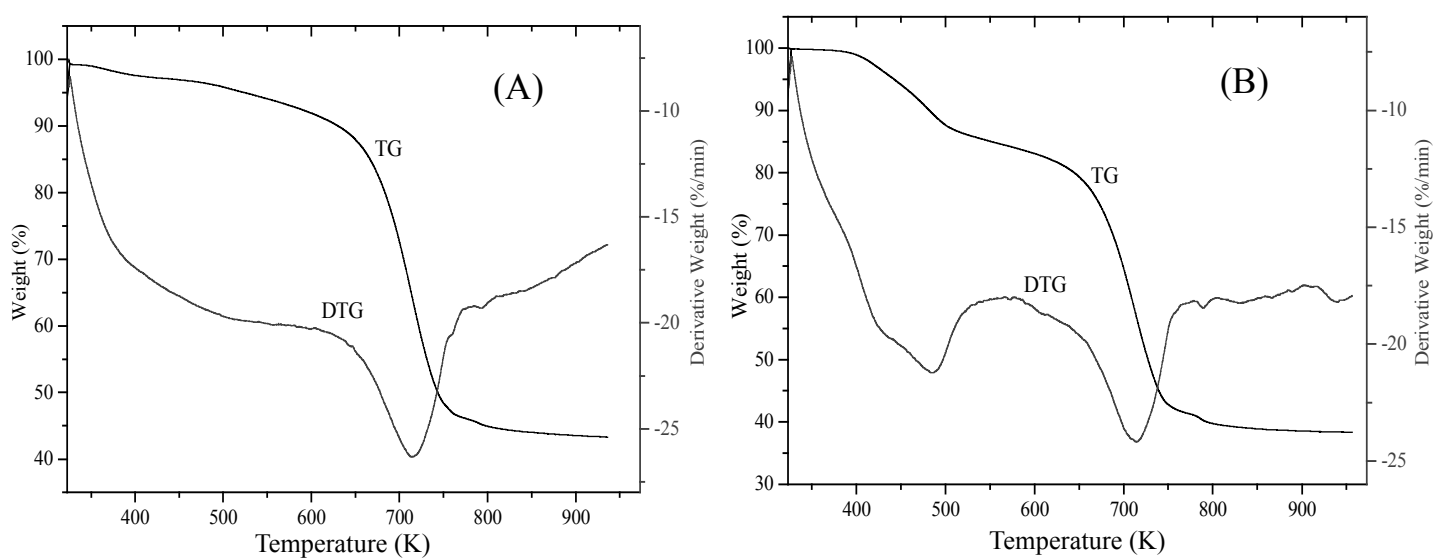

Figure 6. TG and DTG graph of the particles from $\mathrm{pH}=11.5$ at $318 \mathrm{~K}(\mathrm{~A})$ and from $\mathrm{pH}=8.5$ at $338 \mathrm{~K}$ (B)

For the product obtained from $\mathrm{pH}=11.5$ at $318 \mathrm{~K}$ as shown in Figure $6 \mathrm{~A}$, the first weight loss in the range of $323-513 \mathrm{~K}$ is $5.4 \%$, which is due to the loss of absorbed water and water of crystallization. The second weight loss is $51.6 \%$, observed in the range of 513-873 $\mathrm{K}$, which should be attributed to the decomposition of $\mathrm{MgCO}_{3}$ to $\mathrm{MgO}$. After a rough a calculation, the magnesium carbonate hydrate has a simple formula of $\mathrm{MgCO}_{3} \cdot 0.3 \mathrm{H}_{2} \mathrm{O}$.

For the product obtained from $\mathrm{pH}=8.5$ at $338 \mathrm{~K}$ as shown in Figure $6 \mathrm{~B}$, the first weight loss in the range of $323-523 \mathrm{~K}$ is $13.8 \%$, which is due to the loss of absorbed water and water of crystallization. The second weight loss is $48.6 \%$, observed in the range of 523-873 $\mathrm{K}$, which should be attributed to the decomposition of $\mathrm{MgCO}_{3}$ to $\mathrm{MgO}$. After a rough a calculation, the magnesium carbonate hydrate has a simple formula of $\mathrm{MgCO}_{3} \cdot 0.8 \mathrm{H}_{2} \mathrm{O}$.

\section{Reference}

(1) Hong, R. X.; Ju, Y. L.; Chen, S. Q.; Xia, S. P. Chinese J. Chem. Ind. Eng. 1983, 2, 156. 